\title{
Synergistic Effects of $\alpha$-Cypermethrin and Dimethoate against Insect Pests
}

\author{
D. K. KARIUKI ${ }^{* 1}$ J. O. MIARON ${ }^{2}$, A. K. KURIA ${ }^{3}$, J. MUGWERU ${ }^{2}$ AND A. MWAURA ${ }^{4}$
}

'Department of Chemistry', Faculty of Science, University of Nairobi P.O. Box 30197, Nairobi. ${ }^{2}$ Department of Animal Physiology, Faculty of Veterinary Medicine, University of Nairobi, P.O. Box 30197, Nairobi.

${ }^{3}$ Department of Pharmaceutics and Pharmacy Practice, Faculty of Pharmacy, University of Nairobi, P.O.Box 19676-00202 Nairobi.

${ }^{t}$ Department of Pharmacology and Pharmacognosy, Faculty of Pharmacy, University of Nairobi, P.O. Box 19676-00202, Nairobi.

\begin{abstract}
A series of mixture ratios of $\alpha$-cypermethrin and dimethoate insecticides were tested against several insects in the target range of each individual compound to establish the existence of synergism. The $\mathrm{LC}_{50}$ of each target insect was established and then used to evaluate the efficacy of the product. The two products when mixed in a ratio of $1: 27$ ( $\alpha$-cypermethrin: dimethoate) were found to produce a synergistic effect.
\end{abstract}

Keywords: Synergism, pests, $\alpha$-cypermethrin, dimєthoate.

\section{INTRODUCTION}

In the integrated pest management strategy, the paramount objective is the use of less pesticide particularly of the synthetic type. This is often not realized as most of the anthropods either develop resistance, cross-resistance or are not targets of the pesticides. In addition, this is further complicated by the higher number of variety of species of pests targeted by a diminishing class of pesticides with even fewer modes of action on the pests [1]. Under certain conditions, mixtures of pesticides are more effective, allow a broad spectrum of application, reduce the rate of application as well as delay the development of resistance of pests to pesticides [2].

Toxicologically, pesticide formulation with more than one active ingredient is considered to be the same as mixtures of chemicals. The effect of two or more chemicals applied simultaneously will produce a response that may be a simple additive of their individual responses or may be greater or less than that expected by addition of their individual responses. A synergistic effect is the situation in which the combined effect of two or more chemicals is much greater than the sum of effects of each component given alone $[1,3]$.

Synergists were originally used as means of increasing the activity of most insecticides, including natural ones and in the process reduce the cost of insect control. The synergistic effects are greatly influenced by the target pest, formulation ratio, method of administration and Choice of response, either kill or knockdown. However, most common synergists used are themselves non-toxic, natural or synthetic chemicals, which increase the lethality and effectiveness of the pesticides. The mode of action of these synergists is to block the metabolic systems that cCoydd otherwise breakdown insecticide molecules. They therefore interfere with the detoxification of insecticides through their action on polysubstrate monoxygenases and other enzyme systems [4-6].

Synergism has been reported to occur between binary and more mixtures of insecticides on a number of insects [7]. Corbel et al. (2003), reported synergism between binary mixtures of carbamate and pyrethroid classes of insecticides on Culex quinquefasciatus mosquito larvae. This was exhibited when the two insecticides permethrin (pyrethroid) proxpur (carbamate) were mixed at a constant ratio of $1: 60$; based on $\mathrm{LC}_{50}$.

Toxicological effects of organophosphate and pyrethroid as separate individual compounds on pests have been studied. Dimethoate (organophosphate) is used to kill mites and insects systemically and on contact. It is used against a wide range of insects such as aphids, 
thrips, planthoppers and whiteflies in agricultural crops, forestry and animal health. It acts by interfering with the activities of cholinesterase, an enzyme that is essential for the proper functioning of the nervous system of humans, animals and insects. Thus it is a cholinesterase inhibitor and is toxic through all routes of exposure [6,8]. $\alpha$-cypermethrin (pyrethroid) consists of two of the four cis isomers comprising the cypermethrin. It is a highly active broad-spectrum insecticide, effective by contact and ingestion against target pests. This compound is used in agricultural crops, forestry as well as in public and animal health. It is applied as a pour-on preparation for cattle and sheep, dip for sheep and spray for poultry.

In essences, organophosphates are ineffective against Daccus ciliatus through surface contact and oral administration while all the pyrethroids show satisfactory killing ability, rapid and massive knockdown effect. Piperonyl butoxide considerably increases the toxicity of pyrethroids. We can therefore deduce that piperonyl butoxide is a synergist for the pyrethroid $[3,9]$. It is worth exploring the effects of mixtures of pesticides in view of establishing, additive, synergistic or antagonistic action for strategic environmental and pest management interventions.

\section{MATERIALS AND METHODS}

\section{Insects}

Insects of various species were collected and exposed to the three categories of the insecticides. The insects included, mosquito Aedes aegypti larvae (4 $4^{\text {th }}$ instar), cotton bollworm Helicoverpa armigera, cotton stainer Dysdercus fastiatus, desert locust Schistocera gregaria, cockroach Americana periplaneta and vegetable aphids Brericoryne brassicae.

\section{Insecticides}

The technical grades of $\alpha$-cypermethrin (ACP) and dimethoate (DM) were used. A binary mixture (BM) of the two insecticides in ratio of 1:27 ( $\alpha$-cypermethrin: dimethoate) was made. Stock solutions of all formulated products were dissolved in suitable solvents. All the three compounds were stored at a temperature of $4{ }^{\circ} \mathrm{C}$. One $\mathrm{ml}$ each of the stock solutions were diluted in $100.0 \mathrm{ml}$ of water for each bioassay procedure.

\section{Bioassay procedure}

The bioassays followed the standard WHO (1970) [10] protocol with 20 insects in $100 \mathrm{ml}$ of diluted insecticide solution at the given concentration as stated above. The untreated control had $100 \mathrm{ml}$ of distilled water.

\section{Mixture ratio establishment}

The ratio mixture was established through the $\mathrm{LC}_{50}$ using the mosquito larvae Aedes aegypti bioassay. A ratio mixture of 1:27 ( $\alpha$ cypermethrin: dimethoate) was worked out through dose-efficacy. This was established by comparing the knock/kill effect with the corresponding individual compounds.

\section{RESULTS}

Mosquito larvae Aedes aegypti are very susceptible to the BM (Figure 1).

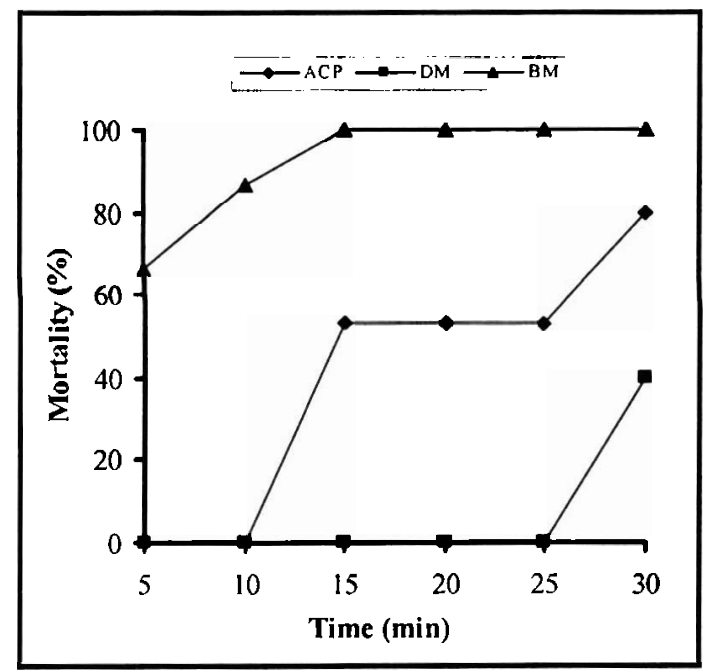

Figure 1: Effect of insecticides on the mortality of Aedes aegypti larvae

Within fifteen minutes all the larvae were killed out compared with about $55 \%$ in the case of $\alpha$ cypermethrin (ACP) and $0 \%$ in the dimethoate (DM) experiment. There was a gradual increase in mortality from 5-10 $\mathrm{min}$ with the $\mathrm{BM}$ mixture compared to zero mortality in $\alpha$ cypermethrin and dimethoate. It is discernible that the additive effect of the individual pesticides would have had a nil effect. Furthermore, at the end of $30 \mathrm{~min}$ there were still live insects in the two individual products. 
Figure 2 shows the bioassay of vegetable aphids Brericoryne brassicae. The aphids were also highly susceptible to the binary mixture compared with the almost zero effect of the dimethoate and in 10 minutes the mixture had a $100 \%$ kill compared with $0 \%$ for $\alpha$ cypermethrin and dimethoate. This could be inferred to mean synergistic effects of the binary mixture on the pests.

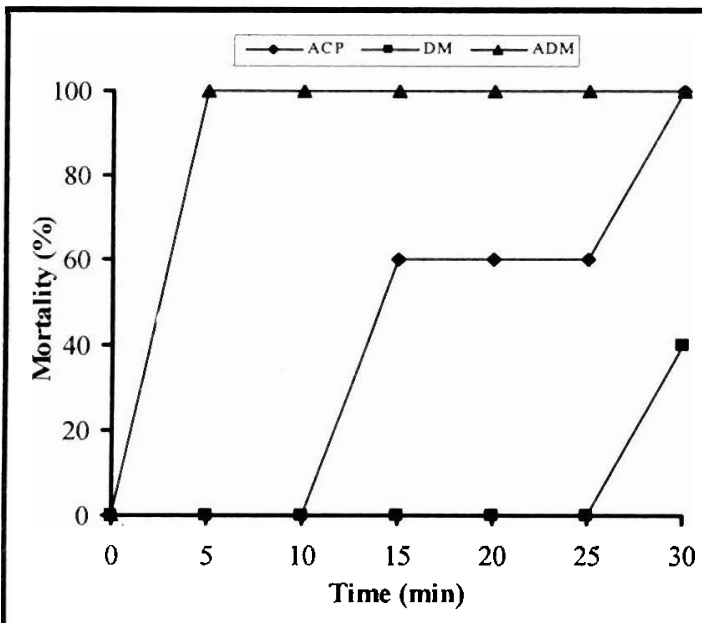

Figure 2: Effect of insecticides on the mortality of Brericoryne brassicae

The cotton bollworm Helicoverpa armigera are also susceptible to all the three pesticides but a higher effect was recorded for the binary mixture (Figure 3 ). Within $10 \mathrm{~h}$ the binary mixture killed $100 \%$ of the insects compared with $60 \%$ and $20 \%$ for $\alpha$-cypermethrin and dimethoate, respectively, clearly demonstrating synergism.

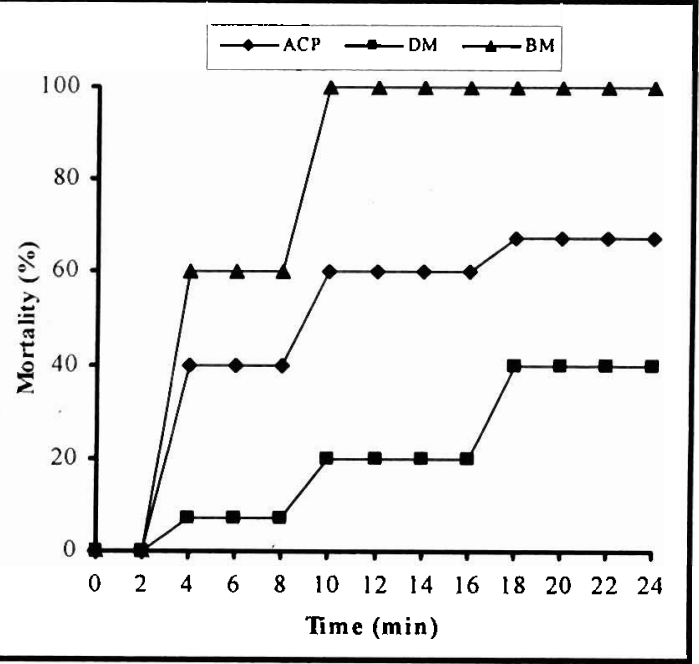

Figure 3: Effect of insecticides on the mortality of Helicoverpa armigera
Figure 4 shows the bioassay of cotton stainer Dysdercus fastiatus mortality rate in $360 \mathrm{~min}$. It was observed that the binary mixture killed $100 \%$ of the insects in 120 minutes compared with $30 \%$ and $0 \%$ for $\alpha$-cypermethrin and dimethoate, respectively. In a total of $360 \mathrm{~min}$, dimethoate killed only $20 \%$ of the insects.

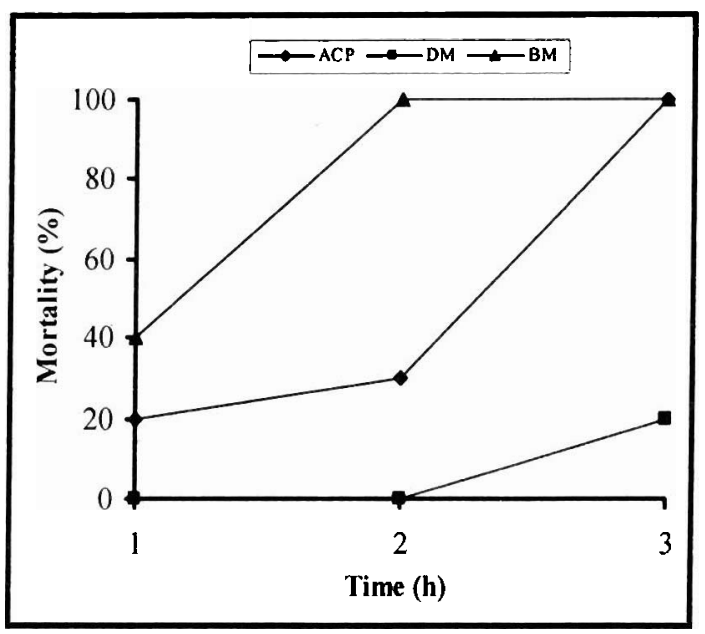

Figure 4: Effect of insectides on the mortality of Dysdercus fastiatus

The desert locust Schistocera gregaria $\left(4^{\text {th }} \& 5^{\text {th }}\right.$ instar) exhibited similar trends of increase in knockdown with time, in all the three products. as shown in Figure 5. In ten hours the mixture killed $100 \%$ of the locust compared with $57 \%$ and $43 \%$ dimethoate and $\alpha$-cypermethrin, respectively. Dimethoate appeared to be more effective on desert locust than $\alpha$-cypermethrin. However, the two individual pesticides were ineffective against the desert locust after ten hours.

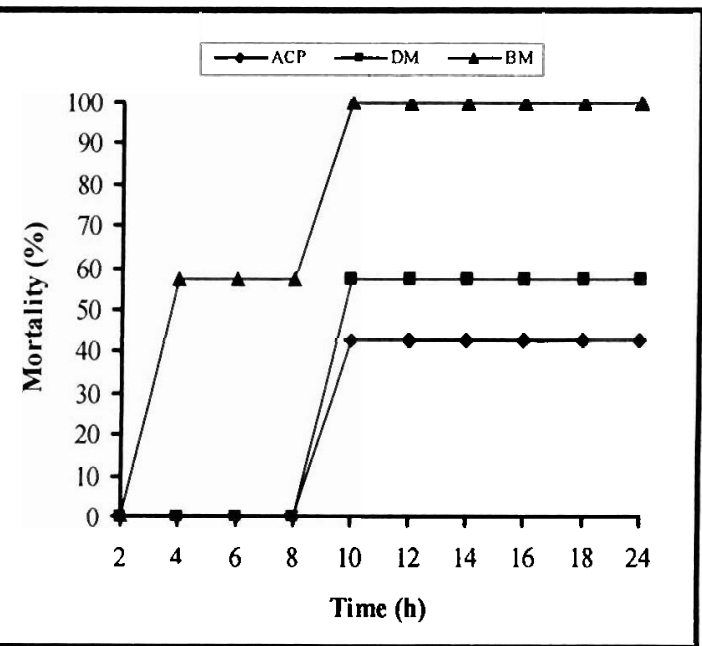

Figure 5: Effect of insecticides on the mortality of Schistocera gregeria 
In Figure 6, the cockroach Americana periplaneta exhibits higher susceptibility to the mixture than to either of the two products. In the first ten hours, the mixture killed all the insects while the two individual pesticides had an effect of $57 \%$ kill. However, the killing effect of $\alpha$ cypermethrin increased to $71 \%$ in the twentyfourth hour while that of dimethoate remained unchanged.

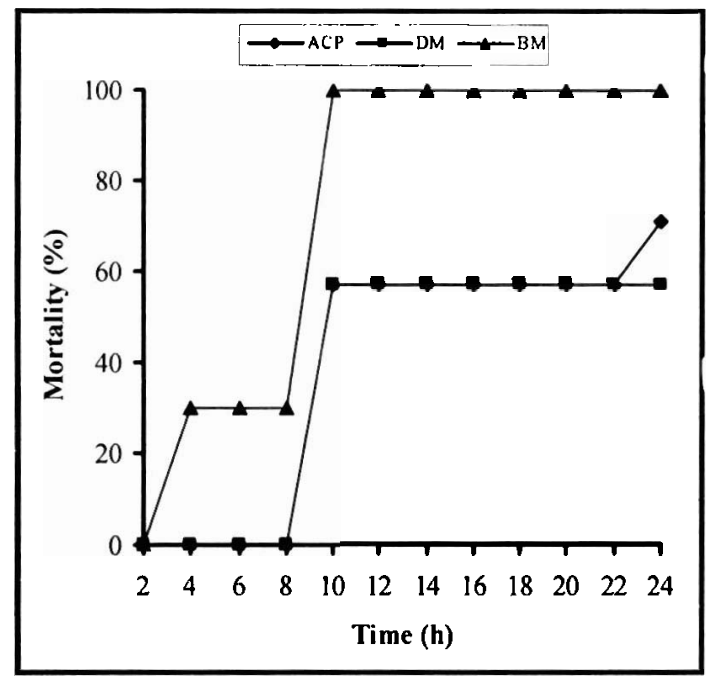

Figure 6: Effect of insecticides on the mortality of Americana periplaneta

\section{Calculation of co-toxicity coefficient}

The synergistic effect is assessed through calculating the co-toxicity coefficient (CC), which gives a quantitative measure of any interaction between two compounds.

On the assumption that the modes of action of the two insecticides $A$ and $B$ are independent, a theoretical $\mathrm{LC}_{50}$ for the mixture was calculated by the formula of Bliss [4]:

$\mathrm{LC}_{50}$ of the mixture $=\left(\mathrm{LC}_{50}\right.$ of $\mathrm{A}$ alone $\mathrm{x}$ percentage of $\mathrm{A}$ in the mixture $)+\left(\mathrm{LC}_{50}\right.$ of $\mathrm{B}$ alone $x$ percentage of $B$ in the mixture).

\section{$\mathrm{CC}=$ Theoretical $\mathrm{LC}_{50} / \mathrm{LC}_{50}$ of the mixture}

The values of $\mathrm{CC}$ significantly $>1$ indicate degrees of synergism, while values $\sim 1$ indicate additive and values $<1$ indicates degrees of antagonism [11]. The binary mixture has a theoretical $\mathrm{LC}_{50}$ of $0.553 \mathrm{mg} / \mathrm{l}$. However, the observed $\mathrm{LC}_{50}$ of the binary mixture is 0.01 $\mathrm{mg} / \mathrm{l}$. The CC of the mixture was therefore 55.3. This is much greater than 1 and hence shows great synergism.

\section{DISCUSSION}

On evaluation we found that $\alpha$-cypermethrin and dimethoate has a synergistic effect against the cotton bollworm, cotton stainer, vegetable aphids, cockroach, mosquito larvae ( $4^{\text {th }}$ instar) and desert locust $\left(4^{\text {th }} \& 5^{\text {th }}\right.$ instar). On applying the $\mathrm{LC}_{50}$ co-toxicity formulae, a coefficient of 55.3 was obtained, indicating synergism between $\alpha$-cypermethrin and dimethoate $(1: 27)$. Comparison of the observed and expected mortalities confirmed this synergism across the investigated pests. The synergistic effect is presumably due to this combination overwhelming the various insect detoxification defense mechanisms by reinforcing their combined impact through different biochemical mode(s) of action. It also reflects variable tolerance (polymorphism) of the target pest spectrum.

The main physiological targets of pyrethroids and organophosphates are respectively, voltagedependent sodium channel and acetyl cholinesterase enzyme, both of which are involved with nerve function of the insect [12]. Dimethoate inhibits acetyl cholinesterase, while $\alpha$-cypermethrin keeps sodium channels open, inducing repetitive impulses, which result in synaptic acetylcholine release and accumulation in the absence of acetylcholinesterase. Synergism has been applied commercially for about 50 years and has contributed significantly to improving the efficacy of insecticides particularly when problems of resistance have arisen and in protecting the environment by having less pesticide application.

\section{ACKNOWLEDGEMENT}

We are very grateful to Orion East Africa Ltd. for providing partial funding and the $\alpha$ cypermethrin and dimethoate used in this research.

\section{REFERENCES}

[1] V. Corbel, F. Chandre, F. Darriet, F. Lardeux and J.M. Hougard, Medical and Veterinary Entomology, 17 (2003) 158-164.

[2] C.B. Bernard and B. J. Philogene, J. Toxicol. Environ. Health 38 (1993) 199 223. 
[3] C.Y. Lee, N.H. Yap, N.H. Chonge and R.S.T. Lee, Bulletin of Entomol. Research, 86 (1996) 675-682.

[4] C.I. Bliss, Annals of Applied Biology, 26 (1939) 585-615.

[5] G.A. Heron, K. Powis and J. Rophail, Aust. J. Entomol. 40 (2001) pp 1-5.

[6] T. Martin, 5 G.O. Ochuo, F. HalaNklo,., J.M. Vassal, and M. Vayssaire, Pest Management Science, 56 (2000) 546-554.

[7] L. Pap, G. Arvai, B. Bertok, Z.K. Ribai, I. Bakonyvari, Pest Management Science, 57 (2001) 186-90.
[8] K.A. Usmani, and C.O. Knowles, J. Econ. Entomol. 94 (2001) 868-73.

[9] A. Maklakov, A. Ishaayal, A. Friedberg, A.R. Yatwetz, I. Horowitz Yarom, J. Econ. Entomol., (2001) 1059-66.

[10] WHO Technical Report Series, (1970) 443. WHO. Geneva.

[11] Y.P Sun, \& E.R Johnson, Journal of Agricultural and Food Chemistry, 53 (1960) 887-892.

[12] J. Hemingway, J. Miller and K. Y. Mumcuoglu, Med. Vet. Entomol. 13 (1999) 89-96. 